\title{
Contextualising the Self and Social Change Making: an Evaluation of the Young Social Pioneers Program
}

\author{
Naomi Berman \\ Foundation for Young Australians \\ Emily Mellon \\ Yarra City Council
}

\begin{abstract}
This article presents an investigation of an Australian social entrepreneurship and leadership program to highlight some of the challenges young social change makers face as they attempt to influence change in their local, national and international environments. The findings from an evaluation of the Young Social Pioneers program demonstrate how reflexive, communicative and participatory practices position young people at the forefront of new forms of civic engagement and that there are certain needs relating to the development of self and community which must be addressed in order that these young social actors can fulfil their civic aspirations. The findings reported here demonstrate that if social entrepreneur programs are to be successful in providing a service to young people, they need to foster the creation of environments characterised by collectivism, collaboration and opportunities for self development while providing practical solutions to common barriers faced by social entrepreneurs. However, whilst youth social leadership programs work to legitimise young change makers, this narrative can also be problematic for young people. The "lone hero" or "solo entrepreneur" tropes pervading the youth leadership and entrepreneurial discourse serve to disguise the realities and structural barriers that young change makers face as they strive to fulfil their social ambitions.
\end{abstract}

\section{Introduction}

During the last decade, a complex reconfiguration of the relationship of government, private corporations and civil society has begun that has enabled new opportunities and spaces for young people to engage in change making on matters that are of importance to them. In this changing environment, young change makers pick and sample from corporate, government and third sector resources and approaches to create more agile organisational vehicles for making social impact. Through innovative social enterprises, these individuals seek to work in between the spaces typically occupied by government, philanthropy or corporate social responsibility arenas. Research indicates forms of participation for young people vary and recently there has been a shift away from institutional or "citizen orientated" action to more “issue-based” participation (Vromen and Collins 2010). Corresponding with what Harris et al. (2010) describe as a "third space”, whereby more "unaffiliated” and highly "informalized" 
modes of participation take place, young people's social action is becoming mobilised around social causes rather than state based political phenomena, traditionally expressed as grass roots activism and social movements.

A key characteristic of the activities of social entrepreneurs is the engagement of local communities in the pursuit of ethical initiatives that speak to greater civic goals. Their commitment to applying novel approaches to social problems across a range of different fields makes social entrepreneurs powerful agents of change. A tenet of community development theory is the notion that social structural change will arise from the deliberative participative actions of a group of people mobilised to address social problems and empower others. In this regard social entrepreneurs are located at the nexus of individual civic participation and community development outcomes. However, beyond community development is the question of how communities are formed; a question which has engaged sociologists for some time (Anderson 1983, Cohen 1985, Tönnies [1887] in Cahnman \& Heberle 1971). Cohen (1985) explores community as a cultural phenomenon, specifically how community boundaries are symbolically defined and the ways individuals develop a sense of belonging to community. Through a process of symbolically constructing community, individuals make 'it a resource and repository of meaning, and a referent of their identity' (Cohen 1985: 118). As will be explored further in this article, this notion of "communities of meaning” is important for understanding the process by which the young social pioneers define themselves and the kinds of social networks or systems required, within a particular grouping or encounter, for the formation of a community of meaning to take place.

\section{The Young Social Pioneers Program}

Since 1999 the Foundation for Young Australians (FYA), a national not-for-profit organisation, has been implementing educational and social action initiatives that promote youth participation. The organisation also has a research arm that conducts and advocates for research highlighting the systemic disadvantages that limit forms of civic and social participation for young people.

The FYA’s Young Social Pioneers (YSP) program, established in 2009, is based on the International Youth Foundation's (IYF) global initiative Youth Action Net (YAN), which has supported over 140 young social entrepreneurs from many countries including: the USA, 
Brazil, Spain, Mexico, Jordan and Israel. The program seeks to develop young leaders who can respond to the increasing challenges of a post-global world (http://www.youthactionnet.org/). FYA has a longstanding affiliation with IYF and this Australian adaptation of the YAN program seeks to address the emerging youth social action landscape while also fulfilling the broader values of FYA around youth empowerment and active citizenship. Designed to fill a gap in social entrepreneur programs which are characterised by business or social enterprise models predominantly for older people, YSP provides a twelve month leadership program for fourteen individuals aged between 18 and 29 years.

To be eligible for the program, a young person must be the founder or co-founder of an initiative which has been in existence for at least six months. During the 12 month program participants are encouraged to expand their initiatives by being given access to a broad range of networks from corporate, philanthropic and not-for-profit sectors and are expected to nurture these relationships consistent with the needs of their individual projects. Predicated on the principles of experiential and flexible learning, the program includes team building activities and workshops designed to develop "hard” or practical skills such as communication, branding and media training, uses of social media, business planning and financial skills. This occurs in a community setting (made up of retreats and workshops) lending to a sense of community and collegial space for shared learning to take place. Development of the person or the "soft" skills and characteristics needed to navigate the complex path of social change are also an integral aspect of the YSP program. In this way, the program progresses along the symbiotic planes of the individual and the group.

Two examples of a Young Social Pioneer are Alissa Phillips and Edwin Kemp Attrill. Alissa established S.P.A.C.E (Specialised Programs and Community Endeavours) in an outer suburb of Brisbane as a community centre with a particular interest in special needs. Since 2007, its fitness and learning programs have provided a rehabilitative service for people living with a disability while fostering relationships between those people and the broader community (http://thespace.org.au).

Edwin is the founder and former Artistic Director of ActNow Theatre a youth led theatre company that works in collaboration with professional artists and young people to create contemporary theatre projects that tackle a range of social issues. Using theatre as a tool for 
social change ActNow operates in a range of community settings including young people in prisons, refugees and migrants, people with disabilities and survivors of trauma and torture.

\section{Contextualising the Self and Social Change Making}

There is an emerging body of literature which highlights the need for greater support of social enterprise activities in young people. Research conducted in 2006 by the Global Entrepreneurship Monitor (Harding 2006) revealed that 'Younger people are more likely to be social entrepreneurs than any other age grouping' (Harding 2006: 3). However, the study also found that as entrepreneurs become more experienced the rate of disenchantment increases. The research concluded that providing young entrepreneurs with networks and guidance is a critical ingredient for building successful social leaders rather than disillusioned entrepreneurs.

An evaluation of the School for Social Entrepreneurs (SSE) highlights the importance of recognising social entrepreneurs as individuals with a diverse set of personal and professional needs (New Economics Foundation 2006: 3). It found there needs to be a greater focus on the individual, particularly developing qualities such as confidence, resilience and passion, as these traits are considered integral to the success of social action initiatives. Participants were found to be over one and half times more likely to succeed when these individual attributes were developed, reinforcing the value of focusing on the individual entrepreneur rather than the social enterprise (New Economics Foundation 2006: 76).

As mentioned above, this notion of building individual capabilities is central to YSP, which is premised on a positive youth development approach; building on an individual's character and existing strengths enables them to 'flourish throughout life' (Park 2004: 40). Character strengths can include optimism, wisdom, social intelligence and teamwork. In addition to promoting wellbeing and providing a buffer against social disadvantage, the development of these personal competencies is considered to lead to an array of personal and social outcomes. As a leadership program, YSP encourages the development of these competencies in an effort to produce broader community outcomes through the creation of young leaders.

A chief objective of social entrepreneur programs is the development of participants such that they are empowered to effect the social change they are committed to. To achieve this, leadership programs draw on a range of development theories and activities that focus on 
enhancing participants’ self-awareness and self-efficacy, along with other skills and competencies, in order to build on their existing talents and improve their civic aspirations and potential. However, there are underlying assumptions to "character building” which have not been adequately explored. It would seem the "social good" attribute of character building, and by extension social leadership/entrepreneur, programs renders the concept somewhat unproblematic. Moreover, deterministic approaches which locate agency in psychosocial constructions such as self-concept and self-efficacy (Bandura 2006) imply that an individual has an 'ability to act intentionally and exercise a measure of control over one's environment and social structures' (Pajares \& Schunk, 2002: 22). This is sociologically problematic as it has a tendency to diminish, or even ignore, the effects of social structure on social outcomes.

Idealistic constructions of young social entrepreneurs are in part perpetuated by romantic, falsely agentic images of young people, particularly those who have ambitions to create social change. Sukarieh and Tannock (2011) describe a "positivity imperative” which manifests in programs designed to empower and engage young people, placing an emphasis on individual agency to the exclusion of the broader social, political, cultural and economic landscape within which these social action initiatives take place. Social leadership and entrepreneur programs unwittingly assume a set of competencies and characteristics that equip young people to overcome their circumstances, to thrive in society and, most importantly, to make a positive contribution to it. Under this positivity imperative, discourses not only homogenise youth experience, but in doing so risk perpetuating the uncritical valorisation of young people and their actions. Furthermore, notwithstanding the systematic marginalisation of young people, such discourses further exclude the experience of acutely disadvantaged groups and in turn deliver an unfair expectation that all young people should have the capacity to effectively participate in social change (see Wyness 2009).

Of salience here is the existence of normative assumptions regarding individuals pursuing social entrepreneurial endeavours. Reuf (2010) explores the prevalence of a "myth of the lone entrepreneur" which serves to romanticise notions of a lone social visionary. Rather, he explains, an important feature of entrepreneurs is their ability mobilise collective action. This notion of entrepreneurial social groups challenges conceptualisations of the solo, "heroic" individual entrepreneur represented in historical treatments by proponents of methodological individualism such as Weber (2003). For Reuf, these ideals, which still have currency today, 
are inaccurate and mask the reality of these individuals whose activities do not only rely on but are in fact embedded in ongoing, durable social (group-centred) relationships.

The evaluation of YSP reported here, while attempting to demonstrate change as a result of program participation, echoes some of these sociological critiques. This article presents the results of the first stage of a three year evaluation which addresses multi-level outcomes, namely, individual, organisational and community. The first year of the evaluation focused on the individual and explored the nature and influence of the program on its participants whilst identifying any underlying barriers to the participants fulfilling on the goals of their initiatives. The remaining two years of the evaluation (currently in progress) will deliver more material about the medium and long term outcomes of participating in this program.

\section{Evaluating the Young Social Pioneers Program}

The evaluation of YSP, conducted by FYA in 2009, was designed to reveal insights into the program's outcomes for young people with regard to their development as social leaders. It also aimed to identify factors that enable or inhibit the fulfilment of the program's aims.

\section{Method}

A qualitative approach based on face-to-face interviews and questions via an online medium as well as the Most Significant Change (MSC) technique was employed to capture key aspects of the participant experience and demonstrate what success looks like for young people in the realm of social entrepreneurship. Aside from a small sample size (13) that precluded the valid use of surveys, these methods were considered best suited to, and consistent with, the principles of the collaborative nature of the YSP program. The individuality of each of the pioneers and their initiatives called for a more nuanced approach to understanding the differing perspectives.

The evaluation centred on an investigation into the extent to which the program contributed to its desired outcomes, rather than making a case for how the outcomes could be wholly attributed to the program. This distinction was based on a relatively new approach, gaining popularity in the field of program evaluation; Contribution Analysis (Mayne 1999). Contribution analysis, in recognising it takes time to achieve an impact beyond what can realistically be achieved in a program and evaluation timeframe, seeks to provide more plausible evidence to counter uncertainty regarding program impacts/effects. Attribution, on 
the other hand, involves drawing causal links and explanatory conclusions between observed changes and a program. Determining whether the outcome was caused by the program is an ongoing challenge and many evaluations identify whether the outcome was achieved and if it was, assume the program can take credit for this (Kotvojs 2006).

In order to build a coherent picture of the participant journey, interviews were conducted during several key stages of the program. A set of questions were also posted on an online platform mid-way through the program to track pioneer progress against their self-identified milestones whilst they were undertaking more ‘solo’ activities. In this way the YSP evaluation took an action research methodological approach (Dick 2002). As internal evaluators we sought to support the program's goal of developing pioneers through the evaluation process whilst seeking to critically examine the process of change taking place. However, it is worth noting there was no formal mechanism for sharing findings with program staff throughout the program (i.e. before write up) and a prearranged structure may have strengthened the action research process.

Data collection for this evaluation was conducted between August 2009 and August 2010 and corresponded to the three key program phases; an initial learning retreat, two weekend workshops and a final retreat. The original 14 pioneers who participated in the 2009 YSP program were included in the evaluation, although due to wellbeing issues, one participant withdrew after the first retreat, leaving a sample of 13.

\section{Interviews}

Face-to-face interviews were conducted at the commencement and then again towards to end of the program. The interviews were on average 20 minutes in length and, with the consent of the participants, involved the use of recording devices (both audio and video). The interviews were structured around broad themes derived from the objectives, these themes were: leadership; organisational (projects); collaboration/partnership; and impact and sustainability. During the middle of the program a series of interview-type questions were posted to an online community platform which spoke to these themes.

In an effort to faithfully capture the participants' intentions, meanings and experiences, the full interview transcriptions were analysed using a "buddy" system. This system involved two members of the evaluation team drawing key themes from the data. The role of the 
"buddy" is to provide an independent and critical view of the data collected. The two sets of interpretations were then discussed and compared, and subsequent conclusions and recommendations developed.

\section{Most Significant Change}

MSC, originally designed for international development programs, is a narrative-based methodology that captures a broad range of subjective experience (Davies 1998, Dart and Davies 2003). It is an innately democratic and participatory method with a strong emphasis on amplifying the "voice” of participants who may otherwise not be heard within the design and implementation of complex initiatives. A key advantage of the technique is that it lends analytic depth and explanatory power to qualitative data and is particularly useful for gaining an in depth understanding of the transformative effects of programs such as YSP.

MSC maps the social processes that are given to change and principally relies on storytelling. However, it differs from a typical narrative methodology in two key ways. The first difference is that the methodology respects the "voice" of participants, avoiding problems in typical qualitative methods where the results derived from stories or interviews depend solely on the interpretations of the researchers. The other difference is that the results have an objective interpretive structure determined by the relationship of the stories to domains derived from program objectives. Although these "domains of change” are widely used in evaluations involving MSC, due to time limitations the decision was made to not apply them here.

A single MSC session was conducted with 10 pioneers (three were absent) during the final retreat (marking the completion of the program). The value of applying MSC in the latter stages of the program is that it provides testimony from participants as to how events are interpreted and what meanings are attached to activities when they have had time to reflect on the past 12 months.

The adaptation of the MSC technique for this evaluation involved three stages whereby stories were collected from each participant in a focus group setting where the larger group was broken down into smaller groups of three to four. Participants were asked to write a story consisting of a single event reflecting practical change (for good or bad) related to the program. In the first selection phase, the most representative stories were selected by the 
participants in their small groups based on the extent of the common experiences they shared, and the meanings or values participants found in the stories. During this time, a scribe was designated in each group who recorded key points from the discussion. This more tangential data forms an equally critical part of the MSC data set along with the selected stories.

In addition to collecting stories of change from participants, a panel of key stakeholders was created to discuss the stories selected by the pioneers in the previous session. The role of the panel was to discuss these stories and make a final selection which would produce just one story. The discussion during this process was recorded, transcribed and validated before being incorporated into the overall analysis. The value of a panel selection session is that it elicits a different set of values and opinion than the participants in the story selection process. Importantly, the panel data adds a more critical (outsider) lens to straight MSC story content which as a participant-led process is more vulnerable to bias. The panel selection data, along with the core MSC data, was analysed alongside the interview data to provide a more comprehensive, multi-perspectival set of insights into the YSP experience.

Participant consent was gained prior to all data collection activities. An important consideration in the reporting of these findings necessarily is the protection of the confidence and privacy of participants. Consistent with the principles of anonymity and confidentiality, identification of participants has been removed in this report. All names corresponding to participant comments derived from the interviews have been replaced with pseudonyms.

\section{Findings: Tool for Social Change}

The evaluation of the YSP program revealed a number of important themes in relation to what young social change makers need when it comes to fulfilling their expressed social purposes. These include the value of being in an environment that promotes a community of likeminded change makers, the refinement of their initiative focus, and gaining insight and expertise in the area of sustainable business practice. Participants identified these as important for the success of their entrepreneurial endeavours and they also derived personal benefit from the experience with many taking the lessons into their non-pioneering activities.

\section{Community of Pioneers}

A key outcome of participating in the program for participants was the creation of a pioneer community which resulted in an elevated sense of collectivism and enhanced opportunity 
through the leveraging of shared goals and experience. The value of being brought together in an environment which is supportive, collegial and encourages reflection was often contrasted against the practical challenges faced by the participants as they navigated the everyday reality of attempting to effect broad social change. Participants described the benefit of the program environment as providing opportunities for not only knowledge acquisition and sharing of ideas, but also collaboration. The program enabled the participant group to become a powerful mechanism for self-generated accountability, responsibility and reflection, as much of their planning and development activities occurred in a peer-to-peer learning environment. Participants expressed an appreciation for the sense of shared experience that stood in contrast to the often isolating experience of leading change:

It's always good to know that you're not out there on your own doing these things, that's been one of the biggest benefits and I think it will continue to be (Steph, initial retreat, 2009).

For the participants, the building of relatedness which refers to having a sense of mutual respect and reliance on others was an important and memorable part of their experience of the program. The importance of having an environment of like-minded individuals in which to 'bounce ideas off' (MSC story, 2009) was echoed throughout the data. This was also coupled with an often observed realisation that they now felt part of a wider community (mobilised around social action) as well as the broader youth-led sector. This location of self within a broader socio-political context crystallised many participants' views of change making and increased possibilities for supported networks. One participant illustrates how this awareness impacted his initiative:

It's just that sort of moment where everyone has that understanding that there is something, that there are people out there who want to support us and who want to help us and we do have friends in wider networks. Just to be able to share that feeling with a bunch of 20 disengaged young people; it's just incredible and they love it and they feed off it and that's fantastic (Daniel, final retreat, 2010).

For the program, providing a supportive environment where young social change makers are surrounded by others working towards similar goals had the effect of stimulating a renewed commitment towards the individual's own initiative. Furthermore, cultivating a mutual 
understanding of the power of the collective was viewed as integral to the achievement of their individual goals. Not dissimilar to Cohen's formation of symbolic communities, an emergent group dynamic was formed and participants synergistically influenced one another towards the attainment of social gains.

The evaluation data revealed that much depends on an environment which actively facilitates dialogue and communication, and the importance of working together and being connected with others through the shared experience of the program. Echoing Ruef's contention, the evaluation has shown that the experience and needs of young social change makers represents the antithesis of a prevailing myth about the lone (pioneer) hero who navigates this social landscape alone. Rather, the strength of peer connections is viewed as vitally important as young leaders value a safe and collegial space to discuss their challenges and how they can leverage the collaborative dimension of their work. The camaraderie often described by participants indicated that the pioneer community alleviates the alienation and despondency felt in some traditional social action initiatives.

While there were substantial benefits to the individual being part of the YSP community, there was also evidence of participants drawing comparisons between their own achievements and that of their colleagues. While this occurred predominantly during the early stages of the program, in some instances this had a negative effect on the individual's sense of efficacy. Theories on self-efficacy posit that the individual's self-assessments of his/her perceived efficacy is not independent of the activities of other (group) members. In short, how an individual gauges his or her degree of efficacy is the result of interactive group dynamics; a socially embedded process rather than individualistic (Bandura 2006: 317). This is a point of significance for youth leadership programs. Young people must be (and feel) supported through their process of reflexivity in a group environment in order that they utilise the experience to strive rather than retreat.

\section{Refining One's Purpose}

While participants came to the program with sufficiently developed, indeed often successful, initiatives, the program was successful in producing a more refined sense of purpose. The importance of achieving a greater sense of clarity around the purpose and goals of their initiative was a key outcome for many of the pioneers. The data suggests having a clearer sense of purpose lead to an increase in confidence and self-belief to initiate a variety of 
diverse relationships. The program in this respect acts as a pull towards a valuable process of reflection. The interim periods between key gatherings allowed pioneers to step outside the day-to-day operations of their initiatives and think strategically about their work. This is evidenced in the remarks of one participant who felt her day-to-day life did not allow for much 'time to see that future goal' and prevented her from:

taking the time to understand what my cause is and all the things that we've been learning ... and how to articulate that. So already in this retreat I feel like I've taken that giant leap forward in knowing what I need to do and how to get there (Marie, initial retreat, 2009).

Participants demonstrated a strong appreciation for developing a deeper understanding of their social purpose and what else was possible. By challenging participants' previous held assumptions regarding their initiative boundaries, these social change makers became highly adept at responding to their circumstances (both opportunities and limitations) to create collaborative civic outcomes:

I think I've just got more clarity. I think when it started I was a bit unfocused I think now I've really connected with what the whole process needs, now I'm actually making it happen whereas before I was kind of going with whatever was happening at the moment but now I can see what a vision for the future could be (Marie, initial retreat, 2009).

This process of "forced reflection" is integral to the expansion of both oneself and the initiative. It provides a critical link between one's ideas and activities. However, with a growing sense of possibility for their initiatives comes increasing frustration at the challenges around fulfilling on these ambitions. The same participant (at a later period) comments on her lack of resources: 'I just don't have the resources or the time to do it'. The remaining evaluation years (the follow up) will add further insight into the outcome of such opportunities and the ways in which the program can support these transitions.

Through the program, pioneers are forced to stop, reflect and refine their objectives. This encourages a clearer and in some cases more meaningful articulation of their project purpose. It is clear from the interview and MSC data that achieving increased clarity around the 
purpose of their initiatives made a significant difference in how the participants viewed themselves as leaders of social change. This reflexive activity made them highly adept at leveraging opportunities to further their initiative's goals.

\section{Sustainability}

The drive to deepen impact and lead a successful social initiative was accompanied by a sense of frustration and anxiety about financial sustainability. It proved to be an area in which almost all participants required knowledge, support and practical expertise. The tools required for such an undertaking are diverse and complex. For instance, across the YSP group, the level of competence around sustainable practices varied considerably and was mirrored by variability in the revenue streams for their initiatives. Whether for philanthropic or social enterprise models, social entrepreneurs require support in understanding financial models and identifying the marketable aspect of their initiative. Young change makers benefit greatly from possessing skills for effectively communicating the economic and social value of their work; to finesse "the pitch" so that investors understand the value. Importantly, achieving clarity of purpose (discussed above) is integral to this process.

A lack of funding sources is a palpable and unavoidable reality for many social entrepreneurs. Although participants were acutely aware they needed to diversify their funding sources, securing interest outside sectors specific to their initiatives proved difficult. The data revealed that there was a sense of powerlessness in generating a wider pool of resources and support. One participant claimed that 'I've been very cautious in who I address for resources’ (Alex, weekend workshop, 2010), adding he only felt comfortable approaching 'like-minded organisations'. Although challenges in the area of funding and support are often a common and expected reality in social entrepreneurship spaces, young people require expertise and assurance to negotiate these challenges. Furthermore, it is in these spaces that FYA and the YSP program are well positioned to advocate on behalf of pioneers, drawing the link between secure funding and greater social change.

The need for advice regarding financial sustainability is concordant with a need for pragmatic solutions to organisational sustainability. Almost all participants wished to hand over their initiative within a few years (whether to another leader or beneficiary community) and skill in succession planning was a highly desired and valued commodity. Not unlike accruing finance, there were varied pathways and levels of required knowledge identified for how 
succession was to occur. The contribution of programs like YSP, in developing the individual's facility in this area, is invaluable in this regard. One participant commented that the eventual test for his organisation was the ability for him to step away, while another described how she wanted 'someone else to come and put their mark on the organisation and take it to wherever it needs to go next' (Katy, initial retreat, 2009). Participants linked financial gain or creating a steady, sustainable organisation with their role as leader. This shared aim and acknowledged responsibility for financial procurement among the participant community was considered beneficial. This attitude underscores the entrepreneurial spirit of the young change maker. Supporting the founders of social initiatives in identifying transferrable skills and robust organisational practices is essential for the growth of social action and leadership.

\section{Conclusion}

This study of the YSP program highlighted how the activities of young social pioneers are characterised by reflexive, communicative and participatory practices which, importantly, place these young agents of social change at the forefront of new forms of civic engagement. A key finding in the evaluation was that the program led to the creation of a pioneer community, enhancing participants' sense of collectivism and opportunity. The program provided an environment in which the young social change makers, surrounded by individuals working towards similar goals, developed a renewed commitment towards their own initiatives. This shared experience strengthened their sense of self and belief in what they could achieve in the realm of social change.

The program contributed to a greater sense of relatedness amongst participants which led to an increase in their motivation to pursue their personal and professional aspirations. This evaluation has shown that the YSP program created an environment that supported collegial relationships as well as autonomy by providing a particular blend of opportunities for collaboration and self-direction. Despite these collaborative efforts, the findings reveal that the question of longevity and durability of these social connections remains extant, and needs to be explored further. Social entrepreneurs face a range of unique challenges, a lack of funding sources being the chief amongst these. For participants, the drive to deepen impact and lead a successful social initiative was accompanied by a sense of frustration and anxiety about financial sustainability. While participants were acutely aware they needed to expand their funding sources, securing interest outside sector-specific areas proved difficult. The 
need for pragmatic solutions to organisational sustainability was highlighted as an important area for development for the participants.

This exploration of young social entrepreneurs participating in a leadership program has reinforced the notion that the self is socially situated. Therefore, one of the key benefits of the program is that it extends the idea that personal achievements have multiple interdependencies that bring together not only the individual social actors but also the right mix of other agents that will bring about desired change. For a program that seeks to galvanize young people wanting to make an impact on their local and broader environments, our findings reveal there are several essential attributes of a program that need to be developed. These include providing an environment that fosters greater depth and quality of connections, the provision of a supportive network of mentors, and skills for developing sustainable business practices and succession planning.

Although the participants were adept at mobilising their communities towards the fulfilment of their discrete ambitions, this evaluation has shown that this cannot be done in isolation and that these young people require a community of likeminded individuals to support their attempts to reshape social life. Improvements in this area will enable youth-led and youthfocused social enterprises to extend, enhance and improve how they make impact.

Indeed, rather than being lone heroes, young social entrepreneurs are dependent on others to achieve their social aims. Ruef (2010) argues that social visionaries create collegial environments, assembling groups around themselves to create a fertile ground for the fulfilment of their social objectives. These findings support this contention, highlighting the practical benefits for young social entrepreneurs of operating within a community of likeminded individuals. They reveal that ongoing and durable social relations are critical for supporting young people's attempts to reshape social life. Furthermore, there remains an ongoing challenge around the risk of these discourses homogenising young people and social experience. YSP is, by its very nature, a program that privileges certain personal capacities of young people as social change makers. The YSP cohort represents a self-selected sample of young people who have demonstrated both their commitment to and success in the design and implementation of ambitious social change projects. 
In presenting the activities of young social change makers as driving action within their communities and leading initiatives for widespread social change, a positive and optimistic narrative of young people's social engagement and agency prevails. However, the findings of this study highlight how the realities and struggles at a ground level as described can be at odds with the more optimistic ways in which young people as social pioneers are sometimes presented. While it is expected that research on social entrepreneur programs depicts and portrays young people from a strengths rather than deficit model of development as demonstrated above, this still risks contributing to an essentialising discourse that valorises achievement to the detriment of ignoring the realities (barriers and myths) which constrain these young people.

While the question of whether the self (particularly a social change maker) can transcend structural barriers was not the focus of this paper, the findings of this study highlight a need for a closer interrogation of the taken-for-granted assumptions operating at a program level and around youth leadership more broadly. This calls for an approach that can reconcile optimistic narratives of young people's agency while identifying barriers that can significantly restrict that agency.

\section{References}

Anderson, B. 1983, Imagined Communities, Verso, London.

Bandura, A. 2006, 'Guide for constructing self-efficacy scales', in Parjares, F and Urdan, T (eds) Self-Efficacy Beliefs of Adolescents, Information Age Publication (IAP): Greenwich.

Cohen, A. P. 1985, The Symbolic Construction of Community, Routledge, New York.

Dart, J. and Davies, R. 2003, 'A dialogical, story-based evaluation tool: The Most Significant Change Technique', American Journal of Evaluation, vol. 24, no.2: 137-155.

Davies, R. 1998, 'An evolutionary approach to organisational learning: an experiment by an NGO in Bangladesh', Impact Assessment and Project Appraisal, vol. 16, no. 3: 243250.

Dick, B. 2002, Action research: action and research, retrieved from http://www.aral.com.au/resources/aandr.html 16 February 2012

Harding, R., 2006, Social Entrepreneurship Monitor, Global Entrepreneurship Monitor, London Business School.

Harris, A., Wyn, J. \& Younes, S. 2010, 'Beyond apathetic or activist youth: ‘Ordinary’ young people and contemporary forms of participation’, Young, vol. 18, no. 1: 9-32.

Kotvojs, F. 2006, Contribution analysis: a new approach to evaluation in international development, Paper given at 2006 International Conference, Darwin, Australia, 4- 7 September 2006. 
Mayne, J. 1999, Addressing attribution through contribution analysis: using performance measures sensibly, Discussion Paper, Office of the Auditor General of Canada, June 1999.

New Economics Foundation 2006, School for Social Entrepreneurs: Evaluation report, October 2006, retrieved from http://www.sse.org.uk/_uploads/File/SSE\%20Report\%20041206.pdf 12 February 2012.

Pajares, F. \& Schunk, D. H. 2002, 'Self and self-belief in psychology and education: an historical perspective’ in J. Aronson (ed) Improving Academic Achievement, Academic Press, New York.

Park, N. 2004, 'Character strengths and positive youth development', Annals of the American Academy of Political and Social Science, vol. 591: 40-54.

Ruef. M. 2010, The Entrepreneurial Group: Social Identities, Relations, and Collective Action, retrieved from http://press.princeton.edu/titles/9214.html 14 February 2012.

Ryan, R.M. \& Deci, E.L. 2000, 'Self-determination theory and the facilitation of intrinsic motivation, social development, and well-being', American Psychologist, vol. 55, no.1: 6878.

Sukarieh, M. and Tannock, S. 2011, 'The positivity imperative: a critical look at the 'new' youth development movement', Journal of Youth Studies, vol. 14: 675-691.

Tönnies, F. 1971, On Sociology: Pure, Applied and Empirical, edited by W.J. Cahnman \& R. Heberle, University of Chicago Press, Chicago

Vromen, A. \& Collin, P. 2010, 'Everyday youth participation? Contrasting views from Australian policymakers and young people’, Young vol. 18, no.1: 97-112

Weber, M. 2003, The Protestant Ethic and the Spirit of Capitalism, Dover Publications, New York.

Wyness, M. 2009, 'Children representing children: participation and the problem of diversity in UK youth councils’, Childhood, vol 16, no. 4: 535-552 